\title{
Globalización de los contratos administrativos mediante las cláusulas paraguas
}

Javier Robalino Orellana ${ }^{1}$

\section{SUMARIO}

1. Breve introducción a la lex mercatoria. Ius Ingeniorum. Lex Petrolea. 2. Cláusulas paraguas y contratos administrativos. 2.1. SCS c. Pakistán. 2.2. SGS c. Filipinas. 3. Las cláusulas paraguas y su importancia para el tema. 3.1. La redacción de las cláusulas y sus consecuencias. 3.2. ¿Qué reclamos están cubiertos por las cláusulas paraguas? 4 . Crítica a la aproximación nominalista. 5. Cláusulas similares.

\section{EXTRACTO}

Las APPs son una opción frente a modalidades de contratación administration más agresivas como aquellas típicas de la época de las privatizaciones. Las APPs conjugan la indispensable colaboración entre el sector público y el privado.

1. Profesor y Director del Area de Derecho Administrativo en la Universidad San Francisce de Quito. Socio de Pérez. Bustamante \& Ponce, Quito. Ecuador. Mi agradecimiento a Mario Navartete por su ap̧oyo en esta investigación. 


\section{LEX MERCATORIA}

La ley comercial moderna tiene sus raíces en la lex mercatoria de la edad media. Esa lex mercatoria igualmente tiene sus raices en los usos y prácticas generales comunes de los comerciantes a través de Europa y que fue aplicada, casi uniformemente, por las cortes comerciales en diferentes países.

En la actualidad, la lex mercatoria ha sido definida como un conjunto de principios generales, de instituciones y reglas, adicionadas a todas las fuentes que han progresivamente alimentado y continúan alimentando las estructuras y el funcionamiento jurídico propios de la colectividad de operadores del comercio internacional, en términos más específicos, son los principios internacionalmente aceptados como ley aplicable a las relaciones contractuales.

La lex Mercatoria se nutre fundamentalmente de los usos y costumbres resultantes del agrupamiento de los modos de comportamiento y prácticas que adoptan de manera particular las fuerzas o agentes que crean e intervienen de manera directa en un mercado específico. Un ejemplo claro del reconocimiento de esos usos y costumbres a nivel internacional son los INCOTERMS (UNIDROIT/PRINCIPLES OF EUROPEAN CONTRACT LAW/ CONVENCIÓN DE LAS NACIONES UNIDAS SOBRE LOS CONTRATOS DE. COMPRAVENTA INTERNACIONAL DE MERCADERÍAS/UPC 600), un grupo de reglas internacionales compiladas de manera uniforme por la Cámara de Comercio Internacional de Paris que sirven como medio de interpretación de las relaciones surgidas con motivo de los contratos de compra-venta internacional de mercaderías. Igualmente, la lex mercatoria se nutre de los contratos tipo de uso común en el tracto comercial internacional y de los pronunciamientos que en la materia son proferidos por los tribunales de arbitramento internacional. 
La dificultad más grande para definir acertadamente la lex mercatoria, es su autonomía. Santi Romano explica que puede ordenarse a un ordenamiento jurídico individual y único que todo cuerpo social suficientemente estructurado constituye un orden jurídico, entendiendo que él mismo comprende, las instituciones y/o mecanismos destinados para el buen uso de las relaciones sociales o la resolución de conflictos. Resultando determinante entonces, el estudiar el factor de la capacidad de coerción del ordenamiento (lex mercatoria) ? en el que ciertamente debe considerarse la existencia efectiva de tal aptitud, esto es, la de la real coerción por parte de la societas? en razón de los medios sociales de contención, referentes al pundonor de los operadores, los cuales se expresan a través de las diferentes sanciones o acciones que pueden emprender los gremios hacía sus miembros sin que con ellas se desconozca de manera alguna los límites de tales conductas, y la remisión obligada de aquellas a los correspondientes ordenamientos. Pues se observa que, a pesar de esa aptitud coercitiva, su reconocimiento por parte de los mismos (ordenamientos), resulta determinante para que proceda su implementación por los correspondientes sistemas. Pues en todo caso, su existencia resulta innegable, por que como se analizará posteriormente, su desarrollo en la práctica comercial internacional y a nivel jurisprudencial, señala claras evidencias sobre esta. Resaltando, que en el mundo de las relaciones comerciales internacionales, las partes tienden a acordar la exclusión de sus disputas de las correspondientes legislaciones locales.

En lo que al pacta sunt servanda se refiere, habremos de anotar que este se constituye como uno de los puntos centrales sobre los cuales ha girado el desarrollo de la lex mercatoria, no sólo en el plano académico sino también en lo que a su recepción por parte de los ordenamientos concierne. Así, se plantea el problema de la ley aplicable al caso concreto cuando media un pacto arbitral, o cuando bien, simplemente se acude ante la jurisdicción estatal para la resolución de la controversia materia sobre la cual omitimos ocuparnos de lo concerniente al aspecto procesal (juez o árbitro que deben conocer, su prelación, procedimien- 
to...), para ocuparnos de lo que respecta a las normas de derecho (ley aplicable al contrato), y reconocer que la escisión entre una y otra materia es palpable, por no tratarse aquí del clásico aforismo: qui eligit iudicem, eligit ius, concepto superado por los distintos ordenamientos, si no bien, por la misma materia que nos ocupa, con alcance global, que impediría en todo caso formular una solución unívoca al respecto.

\section{Ius Ingeniorum}

El Ius Ingeniortum es el producto de la estandarización de los contratos, del uso frecuente de guías técnicas y de los laudos arbitrales. Entre los usos del comercio y los contratos modelo, son estos últimos los que más contribuyen a la creación de un derecho de los contratos internacionales de construcción. Lo anterior encuentra sustento en aquellos países en vía de desarro1lo, en donde es clara la tendencia a la utilización de los contratos tipo creados y desarrollados por el Banco Mundial y FIDIC, y en donde es clara la ausencia de una normativa coherente con las necesidades que se presentan con motivo de la incorporación y ejecución de formas contractuales fundamentadas en esos contratos modelo.

El contenido del ius ingeniorum es el siguiente:

- La realización de estudios previos al proyecto

- Los sistemas de fijación de precios

- Cláusulas de revisión de precios

- Establecimiento de garantías de ejecución de obra, de estabilidad de obra y de pago

- Utilización de la figura del Enginteer

- Cláusulas Penales

- Utilización de los contratos modelo 


\section{Lex Petrolea}

En los últimos treinta años, un número cada vez más grande de laudos arbitrales internacionales relacionados con la industria petrolera han sido expedidos. Estas decisiones proveen material del que se nutre la costumbre internacional. En una demanda contra Kuwait, el Estado argumentó que los conflictos de esta especia han generado una costumbre válida para la industria petrolera -una lex petrolea-que informaba la lex mercatoria.

Según Doak Bishop, la lex petrolea está conformada por:

- Expropiaciones y concesiones

- Nacionalización de contratos

- Legalidad de expropiaciones

- Efecto de las cláusulas de estabilización

\section{Cláusulas paraguas y CONTRATOS adMinistrativos}

Si bien la distinción no ha sido absoluta e inmutable, siempre se ha trazado una línea que separa el derecho local del derecho internacional. Por ejemplo, para accionar la protección diplomática, un mecanismo típico de derecho internacional, se requiere, entre otras cosas, que el estado en contra de quien se dirige el reclamo haya violado una norma en derecho internacional público, y no simplemente normas de la legislación interna.

Ahora bien, el panorama cambia sustancialmente cuando un enfoque internacionalista liberal se desarrolla en la década de 1950 y argumenta que el comercio internacional, la inversión y una protección internacional efectiva de los contratos lograrían la paz y prosperidad (Newcombe y Paradell 438).

A partir de la redacción y vigencia de la Convención de Washington para el tema de los reclamos contractuales y los 
reclamos bajo el tratado adquiere relevancia en vista del particular mecanismo de solución de controversias previsto en la Convención.

Los Estados firmaban tratados de protección y promoción recíproca de inversiones con sus pares, es decir, otros estados, pero eran los nacionales, los inversionistas quienes accedian a la protección prevista en ellos.

Para no ahondar en detalles irrelevantes para el análisis, situémonos en los dos casos SGS que marcaron un antes y un después en este tema. Debemos advertir, sin embargo, que la discusión en ambos casos, se concentraba en la amplitud de las cláusulas paraguas, presentes en el TBI Suiza-Filipinas y SuizaPakistán. Si bien estos casos son importantes, no cubren todas las posibilidades en las que un reclamo bajo el tratado y bajo el contrato puede confundirse.

\subsection{SGS c. Pakistán}

SGS, una compañía de nacionalidad suiza, demandó al gobierno pakistaní el 12 de octubre de 2001, alegando que su inversión había sido expropiada violando así el Tratado Bilateral de Inversiones firmado entre Suiza y Pakistán. Los estándares presuntamente violados fueron: trato justo y equitativo, protección y seguridad plena, y haber inobservado la cláusula paraguas. También ser demandó el incumplimiento contractual por parte del Estado receptor de la inversión. El Estado presentó excepciones a la jurisdicción del Tribunal, que en un laudo parcial se declaró competente sobre las violaciones al tratado pero incompetente sobre el incumplimiento contractual.

En este caso, el Tribunal se enfrentó a una cláusula paraguas de redacción amplia, y sostuvo que una interpretación amplia, en última instancia, podría confundir todo tipo de reclamos contractuales con reclamos bajo el Derecho Internacional, benefi- 
ciando así al inversionista (Newcombe y Paradell 438). Entendiendo de manera restrictiva la cláusula paraguas, el Tribunal pretendía prevenir una expansión casi sin límites de reclamos bajo el TBI que no se relacionaban con una inversión sino con una mera transacción comercial. Además, el Tribunal temía que se estaría arbitrando sobre derecho local, sobre normas dictadas en potestad soberana de los estados.

La decisión del Tribunal fue duramente criticada por varias voces autorizadas, quienes argumentaron que la aproximación restrictiva a la cláusula paraguas atentaba en contra de la voluntad original de las partes -en este caso fue interesante el pronunciamiento oficial de Suiza declarando que su intención original fue la de proteger relaciones contractuales bajo el TBI-, desproveía de sentido o efecto a una cláusula contractual, y no guardaba coherencia con el fin último del sistema de protección y promoción de inversiones. Incluso, autores del renombre de Lluís Paradell han dicho que este laudo no ofrece suficiente coherencia intelectual o mérito académico para constituir un precedente que deba ser observado a futuro.

\subsection{SGS c. Filipinas}

La disputa de SGS contra Filipinas también se relacionaba con la provisión de servicios de inspección pre-embarque de bienes importados de varios países. Durante la ejecución del contrato SGS cumplió con sus obligaciones, avaluadas en alrededor de 680 millones de dólares. El gobierno filipino tan sólo canceló 540 millones, y la disputa se centraba en los 140 millones adeudados.

SGS demandó al Estado el 26 de abril de 2002 por violacio-

nes a los estándares de trato justo y equitativo, protección contra la expropiación y haber inobservado la cláusula Pacta Sunt Servanda (o cláusula paraguas). El Estado presentó excepciones a la jurisdicción del Tribunal, que en un laudo parcial se declaró 
competente sobre las violaciones al tratado y el incumplimiento contractual.

El Tribunal, en este caso, siguió la postura adoptada por el comité ad hoc de anulación del caso Vivendi, que sostuvo:

"[W]here the 'fundamental basis of the clain' is a treaty laying down an independent standard by which the conduct of the parties is to be judged, the existence of an exclusive jurisdiction clause in a contract between the claimant and the respondent state ... cannot operate as a bar to the application of the treaty standard. At most, it might be relevant -as municipal law will often be relevant- in assessing whether there has been a breach of the treaty."

\section{LAS CLÁUSUlas PARAguas $Y$ SU IMPORTANCIA PARA EL TEMA}

\subsection{La redacción de las cláusulas y sus consecuencias}

El artículo 38 del Estatuto de la Corte Internacional de Justicia enumera los métodos que debe aplicar un tribunal o corte al que se someta una disputa de derecho internacional. Los tribunales arbitrales que deciden las disputas relacionadas a inversiones han aplicado los métodos que a continuación transcribimos:

- Las convenciones internacionales, sean generales o particulares, que establecen reglas expresamente reconocidas por los Estados litigantes;

- La costumbre internacional como prueba de una práctica generalmente aceptada como derecho;

- Los principios generales de derecho reconocidos por las naciones civilizadas; $y$

- Las decisiones judiciales y las doctrinas de los publicistas de mayor competencia de las distintas naciones, como medio auxiliar para la determinación de las reglas de derecho. 
En base a estos preceptos, el contenido de los TBIs se ha convertido en la fuente primordial -única en un muchos casos- de derecho sobre la que el juzgador debe fallar, y para interpretar los TBIs, las cortes y tribunales han preferido el método exegético para interpretar sus cláusulas y disposiciones.

Es por esto que los tribunales han prestado especial atención a los términos utilizados en cada Convención para llegar a un entendimiento de lo que las partes pretendian y del alcance de sus disposiciones.

Es por esto que importantes consecuencias jurídicas se han derivado de simples diferencias terminológicas. A continuación repasamos las diferencias en la redacción que han suscitado grandes debates doctrinarios:

\section{i. Observar, asegurar, garantizar o respetar}

Este es el punto alrededor del que se ha suscitado menos debate. La mayoría de las opiniones académicas coinciden en que las palabras observar, asegurar, garantizar y respetar son sinónimos, y que, para efectos prácticos, poseen el mismo valor jurídico; es decir, imponen el deber de no incumplir el compromiso adquirido por el Estado. Solamente existen pocas excepciones en este respecto, con TBIs como Italia-Jordania que dice: "Cada parte contratante deberń crear y mantener en su territorio un marco legal apto para garantizar el tratamiento legal del inversor, incluyendo la ejecución, de buena fe, de todos los compromisos asumidos con cada inversor en particular". El tribunal de Salini c. Jordania entendió que, bajo esa disposición, cada parte contratante no se comprometía a observar alguna obligación que previamente haya asumido respecto de una inversión o inversor en específico [...], ni siquiera garantizaba el acatamiento de acuerdos contraídos entre el estado receptor de la inversión y el inversionista $[\ldots]$, solamente se comprometía a crear y mantener un marco jurídico que permita garantizar el cumplimiento de los 
acuerdos vinculantes a los que se haya llegado con cada inversor.

Otros TBIs, por el contrario, califican el deber impuesto por esta cláusula, y limitan la protección prevista en le cláusula. Este es el caso del TBI Australia-Polonia que dice: "Cualquiera de las partes contratantes deberá, de acuerdo a su derecho interno, y empeñando sus mejores esfuerzos, asegurar que las obligaciones suscritas por autoridades competentes del estado, sean observadas y respetadas."

\section{ii. Obligaciones o compromisos}

Alrededor de esta oposición terminológica, podemos encontrar diferencias de capital importancia, por ejemplo, ¿las obligaciones o compromisos deben vincularse directamente a una inversión? $\mathrm{O}$ ¿basta una relación incidental entre la obligación asumida y la inversión? El proyecto de cláusula paraguas redactado por el OECD argumenta que no basta con que exista una relación simplemente incidental, sino que el vínculo debe ser cierto para poder cubrir compromisos que no se relacionen con una inversión; sin embargo, para los redactores del proyecto mencionado, basta con que un inversionista haya actuado en base a un compromiso aceptado por el estado para que pueda someterse una diferencia a un tribunal internacional.

\section{iii. Inversiones o inversores}

Esta sutil diferenciación puede permitir, en última instancia, que la compañía madre y no sus subsidiarias sean las que presenten el reclamo ante el CIADI o algún foro para resolver diferencias de inversión. $\mathrm{Si}$ la cláusula únicamente se refiere a inversiones, entonces podría entenderse que las compañías madres, es decir, las que financiaron el proyecto, también tendrían ius standi para reclamar por la violación de un estándar de protección.

Revista Ecuatoriana de Arbitraje 
Por el contrario, si la cláusula se refiere a los inversores, entonces solamente tendrían posibilidad de reclamar las compañías que realizaron la inversión, es decir, las empresas subsidiarias.

\section{iv. Asumidas o aceptadas}

La discusión más importante a este respecto se suscita en el tipo de compromisos que puede vincular al inversionista y al Estado. Algunos tribunales han entendido que las obligaciones y compromisos llevan implícita alguna forma de aceptación, lo que nos llevaría a pensar que la protección se extiende tan solo a negocios jurídicos bilaterales. Otras opiniones, por el contrario, sostienen que cualquier tipo de vínculo que ate al estado con el inversionista está protegido por la cláusula. Es decir, no solo contratos u obligaciones bilaterales, sino también actos administrativos y actos normativos de carácter general en base a los que el inversionista haya actuado.

\section{2 ¿Qué reclamos están cubiertos por las cláusulas paraguas?}

De las diferencias explicadas anteriormente, la más importante y que merece especial atención para nuestro análisis es si la cláusula manda respetar todos los compromisos o simplemente los compromisos:

\section{i. Todos los compromisos}

La mayoría de la doctrina, cuando se encuentra frente a una cláusula paraguas que se refiere a todos los compromisos, entiende que son arbitrables las diferencias de origen contractual, e incluso las meramente comerciales. El Tribunal Arbitral del caso Fedax c. Venezuela conoció una disputa eminentemente comer- 
cial, y que se relacionaba con la obligación de cancelar varios pagarés; en el mismo sentido, el Tribunal de SGS c. Filipinas, arbitró una disputa relacionada con un contrato de servicios.

Estos no son casos excepcionales; de hecho, importante jurisprudencia, como los laudos de la disputa entre Joy Mining $c$. Egipto, Eurcko y Noble Ventures, han adoptado esta tendencia. Es más, autores como Schreuer, Crawford, Newcombe y Paradell han secundado esta posición. Según esta postura, si es que no se interpreta la frase todos los compromisos de manera amplia e incluyente, y se limita su aplicación a las disputas de inversión o intimamente relacionadas con una inversión, se estaría desproveyendo de sentido a las palabras, y de esta manera, alejándose de la voluntad de las partes al incluir esa frase.

\section{ii. Obligaciones relacionadas a una inversión}

Si bien la posición contraria es minoritaria, ha sido recogida por los tribunales de los casos El Paso Energy, Pan American Energy, Sempra y Noble Ventures. Ellos sostiene que se debe prestar atención a la naturaleza y objeto de los TBIs; es decir, el derecho de inversión se creó con el propósito de incentivar, precisamente, las inversiones, y sería ilógico pensar que se pretendía dar protección a meras transacciones contractuales y prostituir el arbitraje de inversión.

\section{Crítica a la aproximación nominalista}

Eduardo Silva Romero, aterrizando sus conocimientos filosóficos en materia jurídica, distingue entre la interpretación nominalista y la interpretación realista del texto de un TBI.

La aproximación nominalista cifra la mayoría de sus esfuerzos en la literalidad de la cláusula o el artículo; de esta manera, y como se explicó anteriormente, si es que una cláusula para502 Revista Ecuatoriana de: Arbitraje 
guas habla de todas las obligaciones, mientras otra habla simplemente de obligaciones o compromisos, las consecuencias jurídicas serán importantes.

Como explicamos, utilizando un método exegético de interpretación, a cláusula que se refiere a todas las obligaciones podría entenderse que protege todos los vínculos que aten jurídicamente al inversionista con el estado bajo el derecho aplicable (p.ej.: un contrato o un acto administrativo), incluso leyes o actos normativos de carácter general; mientras que la cláusula que se refiere simplemente a obligaciones o compromisos, no protegerá a todos los vínculos entre el inversionista y el estado, excluyendo así normas generalmente obligatorias ${ }^{2}$.

Frente a esta disyuntiva, autores como Newcombe han recurrido al análisis de la cláusula paraguas realizado por la OECD, quien sostuvo que únicamente serían arbitrables actos unilaterales que estén realmente relacionados con la inversión, es decir, debe existir un vínculo suficiente que debe probarse, ya sea bajo la forma o términos específicos en que el acto o compromiso estaba redactado, o si se puede presumir que el inversor actuó sobre la base del compromiso unilateral. Para la OECD, como se mencionó anteriormente, no bastan meros vínculos incidentales

En el caso SGS c. Filipinas se aceptó que todas las obligaciones, significa que son arbitrables declaraciones unilaterales de voluntad, actos administrativos y normas de carácter general; pero el Tribunal del caso SGS c. Filipinas, opinó que incluso garantías pre contractuales y letters of confort son vínculos que atan al estado.

Hasta ahora, todos los casos mencionados guardan referencia con una aproximación nominalista; la propuesta de Silva Romero es crear conceptos jurídicos homogéneos, que superen las vagas disquisiciones semánticas y puedan crear reglas claras

2. Newcombe y Paradell citan como cjemplo del primer caso el TBI entre las Filipinas y el Reino Unido. y del último los TBIs Pakistán-Suiza y Senegal-Estados Unidos. 
sobre las cláusulas paraguas y el derecho de inversión en general. No tiene sentido crear incertidumbre jurídica por exagerar la interpretación exegética; es decir, los estados signatarios de un TBI deben tener presente las consecuencias jurídicas de los convenios que suscriben, y no pueden estar a la merced de la interpretación de un tribunal.

Si bien las diferencias semánticas son importantes, no podemos sobredimensionar el valor de dos sinónimos utilizados en contextos idénticos. Se debe prestar atención a la redacción literal, únicamente cuando en ella se pueda encontrar la modificación sustancial de una regla, y no solamente cuando se utilizan términos intercambiables de idéntico significado.

\section{Cláusulas similares}

En un inicio, y a la luz de los dos casos SGS, la doctrina sostuvo que frente a TBIs en donde no existía una cláusula paraguas, bastaba con que una cláusula autorice al inversionista a elevar su reclamo por "cualquier controversia" o "cualquier disputa relacionada a una inversión" para que se pueda acceder al foro arbitral. Sin embargo, esta posición ha sido revisada, al punto que se distinguen completamente los reclamos contractuales de los reclamos que puedan hacerse bajo un tratado. 